\title{
Iำ $\mathfrak{n} \mathfrak{n} \boldsymbol{l t}$
}

I. Cinfübrungsgefeł zut \$trafprozefordnung. Bom 1. ge=

Serte bruar 1877 . . . . . . . . . . . . . . 1

II. Strafprozefordunang. Bom 1. Gebruar 1877 . . . . 5

\section{Buth. Augemeine Beftimunugen.}

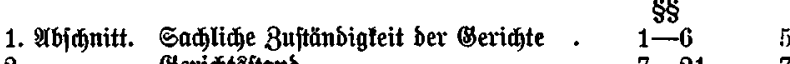

2. "Seridtsftant........ $7-217$

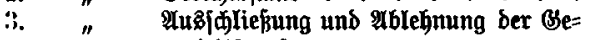
riattsperfonen ........22-'2 13

4. " Beriatliabe Entfajetoungen unb beren Betauntmadung ...... . 33-41 23

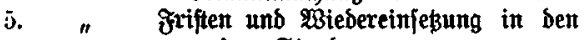
borigen Stand . . . . . . . 42-47 26

6. "Beugent.......... $48-71 \quad 29$

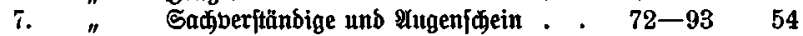

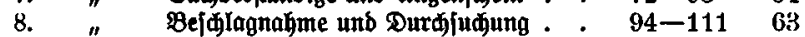

8. " Berfaftung und vorlăufige f̧efntabme. $112-132 \quad 72$

10. "Bertehmung bes Befdulbigtent. . . 133-130 81

11. " Berteibigung . . . . . . 137-150 82

\section{Bum. Berfahren in eriter Suftam.}

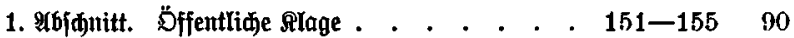

2. " Borbereitung Der üffentliden @lage * 156-17r 91

3. " Beriftlidie Borunterfudung . . . 176-195 98

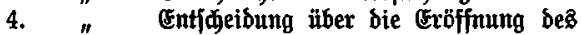
Eauptberfahrents . . . . 196-211 104

5. " Borbereitung ber 5auptberfandrung - 212-224 113

6. " Eauptbertanding ..... 225-275 121

7. " Eauptbertganblung bor ben Satwur= geribten . . . . . . . 276-317 194 8. "Berfafien gegen 2tbwefende . . . 318-337 225 


\section{Bud. Med̆t8ిmittet.}

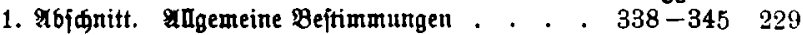

2. " Beímberbe. . . . . . . . 346-353 235

3. " $"$ Berufung . . . . . . . . . $354-373238$

4. " Mebifiou . . . . . . . . . 374-398 244

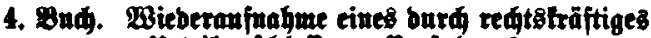

Itteil gefdiffeuen Berfahreus $\quad 399-413 \quad 266$

5. Buq. Beteiligung bes Berlekten bei bem Berjahren.

1. \$bifnitt. \$ribattlage. . . . . . . . . 414-434 273

2. $"$ Rebentlage. . . . . . . 435-446 282

6. Bum. Befoubere arten bes Berjahreng:

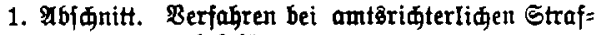

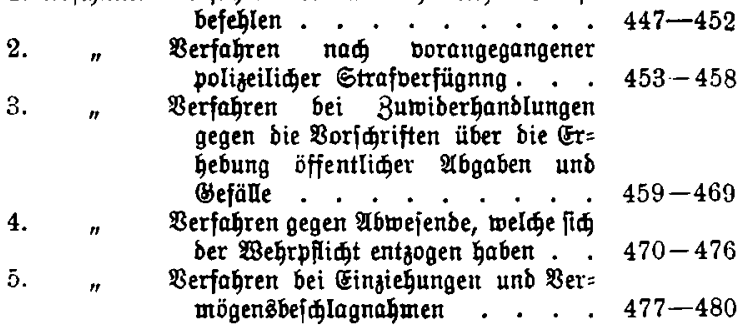
290

7. Bud. Strajpolftredung und Stoften bes Berfahrens.

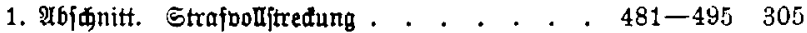

2. "Soften bez Berfagrents . . . . . 496-506 310

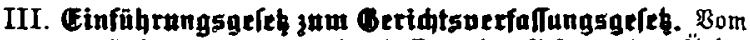

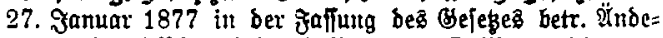

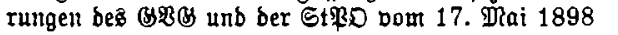

IV. Gefeh, betreffend die Beltung des Berimtsoerfafungsgeletes in felgoland. Bom 4. Juni 1893 . . . . 326

V. Berihtsuzrfalfungsgefet. Bom 27. Januar 1877/17. Miai 1898/5. Juni 1905/1. Эuni 1909.

1. Titel. ßidterant . . . . . . . . . . 1-11

2. " Beridtebarteit. . . . . . . . . 12-21

3. " Amtogerimte. . . . . . . . . 22-24

4. " Sकöffergeridte . . . . . . . . 25-57

5. " Sanbgeridte . . . . . . . . . 58-78

6.

Sdmurgerifte . 


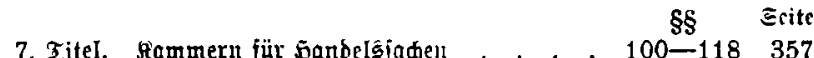

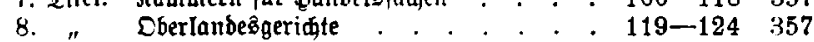

9. " Reidzgeridt. . . . . . . . 125-141 358

10. " छtantảnmaltiduji . . . . . . 142-153 362

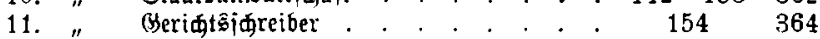

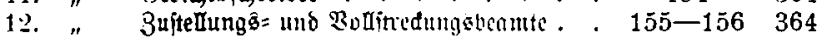

13. " आedtăhilfe . . . . . . . . . 157-169 365

14. " Efientligteit uno डißungspolizei . . . 170-185 368

15." "Beridtżprame . . . . . . 186-193 375

16. " "Eeratung und : sbitimmuny . . . . 194-200 378

17. " Beriftsferier . . . . . . . . 201-204 380

\section{Ininang.}

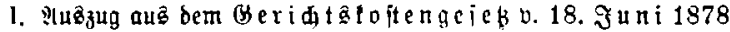
in ber gaffung ber Betanntmađung vom 20. Mai 1898 unb

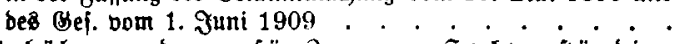

II. Sebührenorbnung für $३ e u g e n u$. Sa

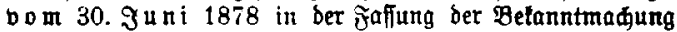
bom 20. 9iai 1898

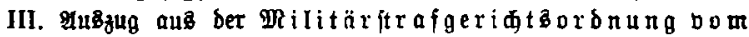
1. De zember 1898 . . . . . . . . . . . .

1V. Befeb, betr. Die Entidäbigung ber im wieder= aufrabmeverfagren jreigeiprodenen Ber fonen, bom 20. Ma $i 1898$. . . . . .

V. (3) ejeb, betr. bie Entifäbigung für unf两ulbig erlittene unterfudungagat, bom 14. Juli 1904

Gadregifter

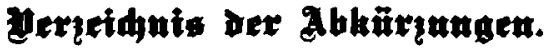

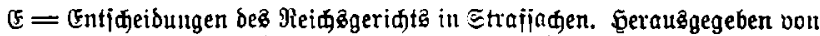

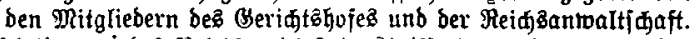

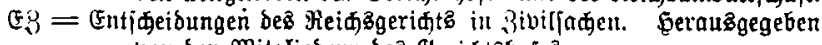

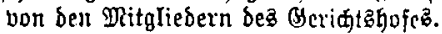

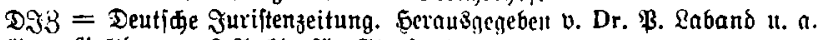
( $)=$ (Soltbammer: Ir fio für Strafiedt.

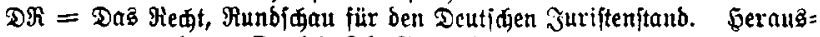
gegeben v. Dr. $\overline{\$}$. $\mathfrak{T h}$. Evergel.

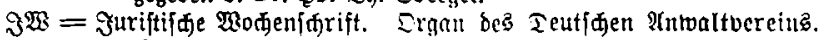
$\mathfrak{B r}=$ Breustjąes.

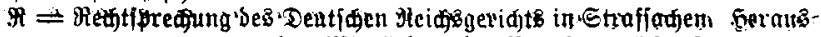
gegeber von ben Mitgliebern ber Mteidizantmaltidaft.

भB९l = Bentralblatt für bas Deutfale Neid.

$\mathfrak{u}=$ urteil. 